\title{
85684 - COMPARAÇÃO DA FORÇA DE PREENSÃO PALMAR E DESEMPENHO FUNCIONAL EM IDOSOS LONGEVOS
}

\author{
Pôster - Gerontologia
}

Nathalia Griebler / GRIEBLER, N. / UFRGS; Tainara Steffens / STEFFENS, T. / UFRGS; William Santos / SANTOS, W. / UFRGS; Caroline Pietta Dias / DIAS, CP. / UFRGS

Introdução: A população acima de 80 anos está cada vez maior, essa fase é acompanhada por mudanças neuromusculares que resultam em processos degenerativos, entre eles declínios funcionais e diminuição da força muscular ${ }^{1}$. Objetivos: Comparar a força de preensão palmar e o desempenho funcional em idosos acima de 90 anos de idade. Métodos: A amostra foi composta por 61 idosos longevos com idade acima de 90 anos. O estudo foi aprovado pelo Comitê de Ética em Pesquisa da Universidade Federal do Rio Grande do Sul (nº 2.465.359) e os participantes assinaram um Termo de Consentimento Livre e Esclarecido. Os idosos foram agrupados em três estratos etários: 90-92 anos ( $\mathrm{n}=27), 93-95$ anos $(\mathrm{n}=19), 96$ anos ou mais $(\mathrm{n}=8)$. Para a avaliação da capacidade funcional realizaram o teste de sentar e levantar de uma cadeira (SL) e o teste Timed up and Go (TUG), para força de membros superiores o teste de preensão palmar (PP). Resultados: Quando divididos por estratos etários, os valores médios encontrados para o TUG, SL e PP foram de $14,93 \pm 5,87 \mathrm{~s}, 15,52 \pm 4,44 \mathrm{~s}$ e $16,72 \pm 4,76 \mathrm{~kg} / \mathrm{f}$ no grupo etário de $90-92$ anos, $24,05 \pm 13,15 \mathrm{~s}$, $20,93 \pm 10,03 \mathrm{~s}$ e $19,15 \pm 5,90 \mathrm{~kg} / \mathrm{f}$ no grupo de $93-95$ anos e $19 \pm 7,95 \mathrm{~s}, 20,29 \pm 7,43 \mathrm{~s}$ e $14,60 \pm 6,14 \mathrm{~kg} / \mathrm{f}$ para o grupo de 96 anos ou mais. No TUG foi observado um melhor desempenho no grupo etário de 90-92 anos, quando comparado com o grupo de 93-95 anos ( $\mathrm{p}=0,008)$. No teste de PP, quando comparados os grupos de 96 anos com os de 93-95 anos, foi encontrada uma menor força no grupo mais idoso ( $\mathrm{p}=0,042)$. Quando comparados os estratos de 90-92 anos com os indivíduos de 93-95 anos $(p=0,52)$ não foram observadas diferenças significativas. Já no teste SL, não foram observadas diferenças significativas entre os grupos ( $p>0,05$ ). Conclusões: Os indivíduos entre 90-95 anos não apresentam alterações de força, já acima de 96 anos estima-se uma perda considerável. Em idades acima de 96 anos os resultados apontaram maior declínio de habilidades funcionais que necessitem de força muscular de membros inferiores.

Palavras-chave: nonagenários; funcionalidade; força muscular.

Referências: 1. DALLA LANA, L; SCHNEIDER, R.H. Síndrome de fragilidade no idoso: uma revisão narrativa. Revista Brasileira de Geriatria e Gerontologia, v. 17, n. 3, p. 673- 680, 2014. 